LINGXIANG WEI, M.Eng. ${ }^{1}$

E-mail: weilx@ycit.edu.cn

PENGFEI ZHAO, Ph.D. ${ }^{2}$

(Corresponding author)

E-mail: zhaopengfei@bucea.edu.cn

YUXUAN LI, Master's Degree Candidate ${ }^{3}$

E-mail: liyx_hello@emails.bjut.edu.cn

YINJIA CHEN, Bachelor's Degree Candidate ${ }^{1}$

E-mail: chenyinjia1413@163.com

MINGJUN LIAO, Ph.D. ${ }^{1}$

E-mail:mjliao@163.com

${ }^{1}$ School of Materials Science and Engineering

Yancheng Institute of Technology

211 Jianjun Road, Yan Cheng City,

Jiangsu 224051, China

${ }^{2}$ School of Civil and Transportation Engineering

Beijing University of Civil Engineering and Architecture

15 Yongyuan Road, Daxing District,

Beijing 102616, China

${ }^{3}$ Beijing Key Laboratory of Traffic Engineering

Beijing University of Technology

100 Pingleyuan, Chaoyang District,

Beijing 100124, China
Traffic Engineering

Original Scientific Paper

Submitted: 2 Nov. 2020

Accepted: 1 Mar. 2021

DOI: $10.7307 /$ ptt.v33i4.3740

\title{
BEHAVIOUR ANALYSIS OF LEFT-TURNING MOPEDS AT SIGNAL CONTROLLED INTERSECTIONS - A CASE STUDY IN YANCHENG CITY
}

\begin{abstract}
Mopeds (electric bicycles and light motorcycles) are commonly used as a personal transportation mode in China. However, the understanding of characteristics of left-turning mopeds at signal-controlled intersections has been relatively limited. To bridge this gap, firstly, this paper proposed a video conversion method of moped movement data acquisition. Then, a method of data accuracy verification was introduced by comparing the results between the field experiment and the video conversion method. Secondly, the ideal traffic space for left-turn mopeds from different entrances was defined to analyse the characteristics of the left-turning mopeds at intersections. Further, three indicators, namely, transverse distance, the proportion of left-turning mopeds with crossing behaviour, and the average number of avoidance behaviour, were proposed and used to analyse the asymmetrical characteristics behaviour, crossing behaviour, and avoidance behaviour. Finally, based on empirical data collected from five signal-controlled intersections, the proposed methods and behaviours were analysed. This paper provides both a valid method of obtaining the position data of mopeds and a reliable basis for improving the safety of left-turning moped riders at urban signal-controlled intersections.
\end{abstract}

\section{KEYWORDS}

traffic engineering; riding behaviour; left-turning moped traffic flow; signal-controlled intersection.

\section{INTRODUCTION}

Mopeds (including electric bicycles, also known as e-bikes, and light motorcycles) are a relatively new type of vehicle that have emerged to provide favourable characteristics such as being lightweight, low cost, and high speed. Besides, mopeds using electricity as a source of power produce less pollution and consume less energy than many motor vehicles [1-4]. Since mopeds can maintain a certain speed using less fuel, their carbon emissions are significantly lower than those of cars travelling at the same speed and similar distances. Therefore, mopeds have become the main choice for short-distance travellers in many Chinese cities $[5,6]$. In 2012, global moped sales reached 31 million, and in 2018, 47.6 million [7]. As of 2016, the number of mopeds in China reached more than 250 million and continues to increase rapidly with an annual growth rate of $9.4 \%[8,9]$. 
At present, a rapid increase in the number of mopeds as a mode of transportation has dramatically changed the urban traffic situation negatively. Nonetheless, traffic management departments have not focused enough attention on mopeds at signalised intersections and have not taken effective measures to manage mopeds. At signalised intersections, mopeds robbing, encroaching on the driving space of motor vehicles, and occupying motor vehicle lanes are important reasons why the traffic capacity of urban road networks has been reduced and traffic accidents have increased [10-12]. To ensure the safety of road users, it is necessary to study the driving characteristics of mopeds at signalised intersections. Due to the large number and irregular driving curves of mopeds, a lack of left-turn guidelines for mopeds, and their proximity to other left-turning vehicles, illegal behaviours of the left-turning moped riders at signalised intersections are key causes of moped traffic accidents [13-15]. From 2012 to 2016, a total of 193,000 road traffic accidents involving mopeds occurred in China, resulting in a total of 37,700 deaths $[16,17]$. Among those traffic accidents, 56,200 were caused by mopeds and resulted in 8,431 deaths, giving the rate of accidents caused by mopeds of $29.1 \%$, and the death rate of $22.3 \%[18,19]$. Zhang and colleagues analysed moped accidents in a city in China and found that nearly $64 \%$ of these accidents were caused by motor vehicles [20].

China is not the only country with a high incidence of moped-related traffic accidents. In Iran, moped-related traffic accidents represented a major problem. In 2014, 5,270 people lost their lives due to accidents on roads, and 930,000 were seriously injured. In Sweden, the death rate of moped-related accidents reached $8 \%$ of the total traffic accidents in 2016. Moreover, accident and fatality rates of traditional bikes are high in other large cities in Europe [21]. Therefore, understanding the characteristics of mopeds to improve traffic conditions has become an urgent problem that remains to be solved by traffic management agencies.

To date, a great deal of research on mopeds has been carried out around the world. To reduce traffic accidents involving bicycles in developing countries, a bike accident model was constructed and used to design bicycle lanes [22]. Juremalani et al. demonstrated the benefits of using non-motorcycles in cities [23]. Wang et al. showed that traffic accidents caused by non-motor vehicles can be reduced by introducing reasonable traffic organisation methods [24]. Simi- larly, Damsere-Derry et al. analysed traffic accident data in northern Ghana and showed that further planning of traffic infrastructure is required to reduce traffic accidents associated with sharing of road space between non-motor and motorcycles [25]. In South Korea, the number of traffic accidents caused by mopeds accounts for a large proportion of the total traffic accidents. To decrease the number of traffic accidents and ensure the safety of cyclists, Lee et al. proposed automatic emergency braking for bicycles [26].

To investigate cyclist casualty rates in developed countries in Europe, Leo et al. analysed injuries to cyclists due to traffic accidents based on traffic accident data from Sweden and the Netherlands [21]. Otte et al. compared and analysed data on injuries sustained by traditional cyclists and moped riders and concluded that wearing helmets can effectively reduce injuries and mortality rates [27]. Ou et al. studied the driving characteristics of mopeds at signalised intersections and proposed a set of rules for the use of public mopeds to ensure safety [28]. Liu et al. found that improving the awareness of traffic safety issues among cyclists is one of the most important ways to solve traffic accident problems [29].

In addition, a large body of research exists on moped drivers, from the basic characteristics of scooters to traffic efficiency. Cherry used survey data to analyse the basic relationship between three parameters of traffic flow on-road sections and traffic characteristics of electric bicycles at intersections [30, 31]. Rose established a travel demand model for electric bicycles based on supply and demand in urban areas $[32,33]$. Bang proposed a classification criterion for determining the influence of non-motorcycles on motorcycles based on lateral friction factors [34]. Ye analysed electric bicycle and bicycle traffic characteristics and introduced the concept of a bicycle effective driving area [35-36]. Han and others used traffic survey data to perform an in-depth study of relevant traffic characteristics of electric bicycles and used regression analysis and other methods to derive some basic laws of traffic behaviour [37, 38].

In summary, research has mainly been performed from the perspective of vehicle right-of-way and associated conflicts, whereas few studies have addressed the placement of mopeds on-road sections and intersections and the association with traffic conflicts. Studies on the characteristics of moped riders are relatively limited [39-41]. 
To this end, this paper analyses the spatial riding characteristics of left-turning moped riders at signal-controlled intersections. Firstly, a data acquisition scheme for collecting the spatial riding characteristics of moped riders at five signalised intersections was established. Then, a systematic mopeds analysis method was proposed, based on the different riding areas and behaviours. Further, based on the empirical moped riding data, the proposed method was tested, and the characteristics of left-turning mopeds were systematically and comprehensively analysed.

\section{DATA ACQUISITION AND PROCESSING}

In this section, we introduce the method of mopeds' movement data acquisition and then describe the method of verifying the effectiveness of the data acquisition method through a field experiment.

\subsection{Original data collection}

To obtain the original data of moped movement, five typical signal-controlled intersections with protected left-turning phases were selected in Yancheng, China. All these left-turning mopeds enter intersections from entrance lanes in four directions, namely east, west, south, and north. The width of these entrance lanes is 5 meters. In addition, the medians between the motor vehicle lanes and non-motor vehicle lanes are set to separate the left-turning lanes for motor vehicles for each of these five surveyed intersections.

In terms of signal control, these five surveyed intersections have the same traffic signal phase sequences and the same signal timing schedules.
All the surveyed intersections are four-phase intersections with two protected left-turning phases and two straight phases. The green light duration of the left-turn phase is 30 seconds and the yellow light duration between the green light and the red light is 3 seconds. There is no all-red time for these intersections.

A photography-based method was selected for moped riding behaviour data acquisition. The videos that include the whole process of passing the intersections of mopeds at five signal-controlled intersections were captured over a certain period by cameras placed above these intersections. The videos of the bird's eye view of these intersections were recorded during morning peak times (7:30$8.30)$, afternoon peak hours (11:00-12:00), and evening peak times (17:30-18:30) of weekdays. To avoid the influence of traffic flow fluctuation on the behaviours of moped riders, the morning peak time on Mondays and the evening peak time on Fridays were excluded.

After recording, these videos were analysed by the Adobe After Effects software second by second. And then the coordinates of mopeds were recorded manually according to the grid at the intersection at the interval of 1 second. According to the geometrical characteristics of the intersection, the perspective mesh tool of Photoshop was used to select the four intersections of the non-motor vehicle parking extension lines, and the perspective grid plane corresponding to the intersection road plane was determined. Video images were pre-processed to ensure that the position of mopeds and vehicles on the grid perfectly corresponded to their relative position in the video screenshots, as shown in Figure 1.

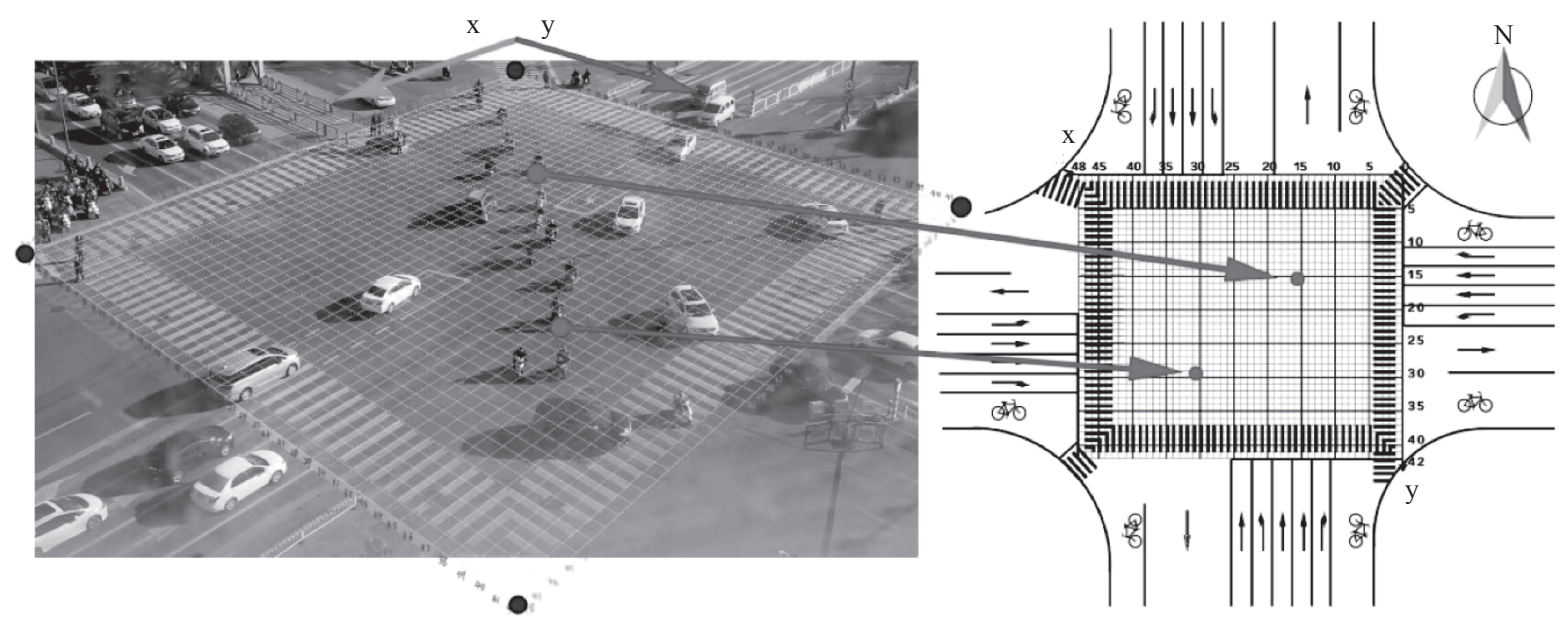

Figure 1 - Schematic diagram of the video coordinate method (An example) 


\subsection{Verification of data acquisition method}

To verify the effectiveness of the data acquisition method, analogue data acquisition in the form of video recordings was carried out in various open spaces and from various observation angles and heights. Measurement accuracy was confirmed by comparing the $\mathrm{x}$ and $\mathrm{y}$ coordinates, namely the actual physical distance in the two-dimensional space, measured in the field with the results from processed video data (Figure 2).

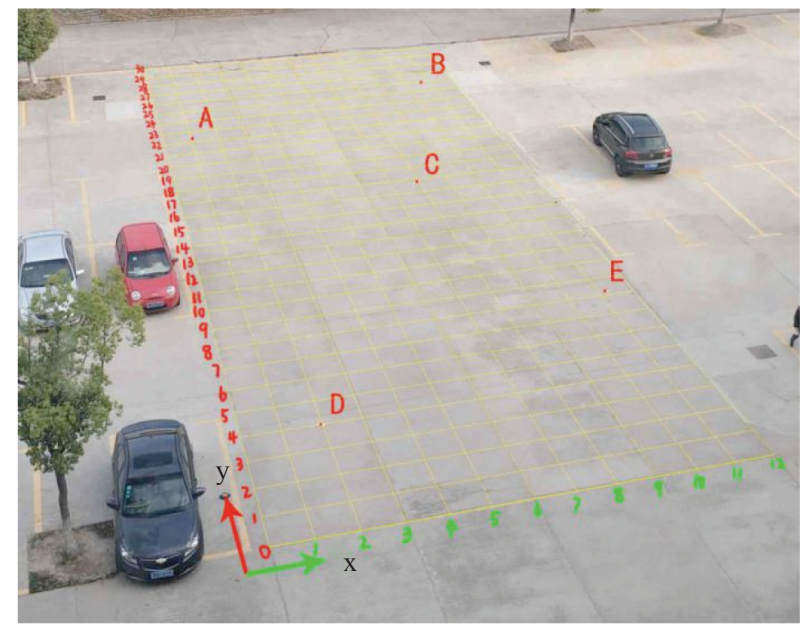

Figure 2 - Diagram of the simulation experiment

A simulation of an intersection was set up in an open space and five marks, namely A to E, were made on the ground. By comparing the actual coordinates of the marks with the converted coordinates of each marked location from videos filmed at high altitudes, the coordinate error was obtained (Table 1).

Based on the final field measurements and video conversion coordinate data, the error was found to be 0.1 meters and the $x-y$ data reading unit was accurate to 0.1 meters; therefore, this data acquisi-

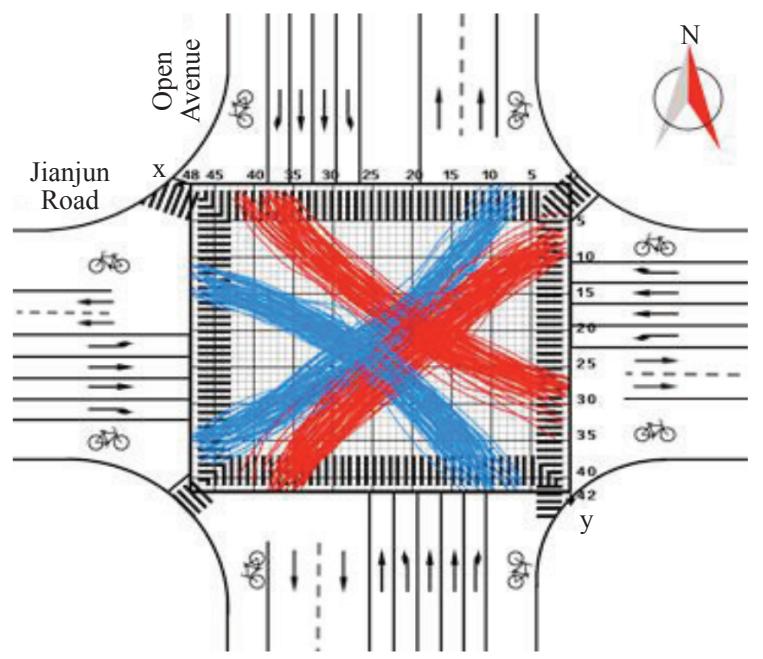

Figure 3 - Riding trajectories of left-turning mopeds

tion method is effective. Coordinates of each moped at each moment in time (location of front-wheel or rear-wheel contact point) were recorded by manual observation every 1 second to establish a dataset. On the completed coordinate grid, the vehicle running for 1 second is taken as the timing unit, and the driving track points of each moped are marked by manual punctuation. Then, the coordinates were calculated and converted to obtain a coordinate map, and thus, the original displacement data for the riding characteristics of a single moped and moped groups.

From the $x-y$ coordinate data, the traffic trajectory of each moped rider while turning left can be depicted, as shown in Figure 3.

\section{MOPED RIDERS BEHAVIORAL ANALYSIS METHODS}

To analyse the characteristics of the left-turning mopeds at intersections, we first defined the ideal traffic space for left-turn mopeds from different

Table 1 -Results of the field experiment and the video conversion method

\begin{tabular}{|c|c|c|c|c|}
\hline Tags & Coordinate & Measurement [m] & Video conversion $[\mathrm{m}]$ & Error $[\mathrm{m}]$ \\
\hline \multirow{2}{*}{ A } & $x$ & 1.0 & 1.1 & -0.1 \\
\hline & $y$ & 22.4 & 22.4 & 0 \\
\hline \multirow{2}{*}{$\mathrm{B}$} & $x$ & 10.7 & 10.7 & 0 \\
\hline & $y$ & 25.9 & 26.0 & -0.1 \\
\hline \multirow{2}{*}{$\mathrm{C}$} & $x$ & 7.9 & 7.9 & 0 \\
\hline & $y$ & 16.7 & 16.8 & -0.1 \\
\hline \multirow{2}{*}{$\mathrm{D}$} & $x$ & 2.0 & 2.0 & 0 \\
\hline & $y$ & 4.0 & 4.0 & 0 \\
\hline \multirow{2}{*}{$\mathrm{E}$} & $x$ & 11.2 & 11.2 & 0 \\
\hline & $y$ & 8.1 & 8.2 & -0.1 \\
\hline
\end{tabular}




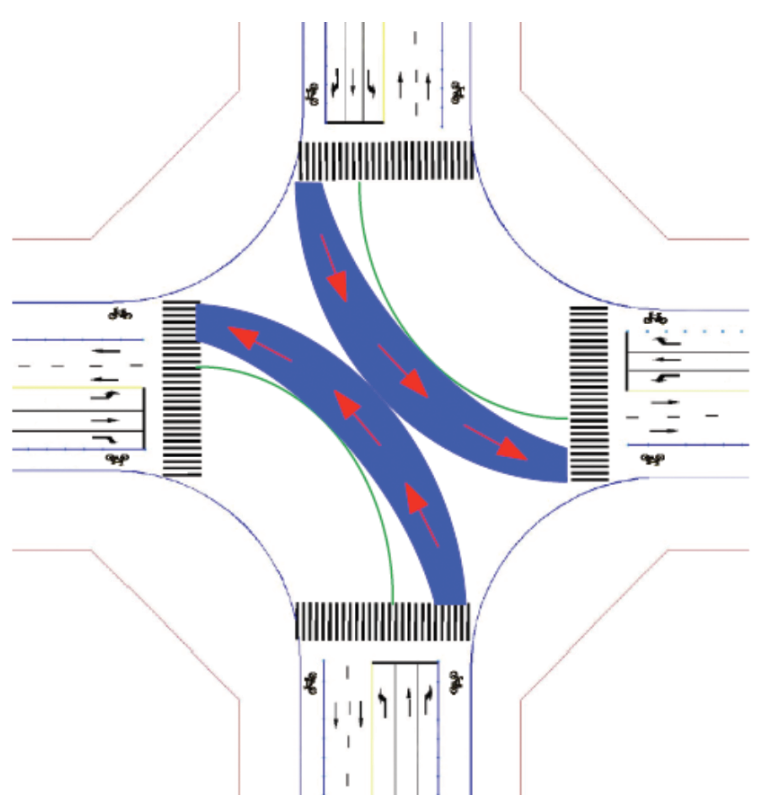

a)

Ideal traffic space of
left-turning mopeds

Driving direction of left-turning mopeds

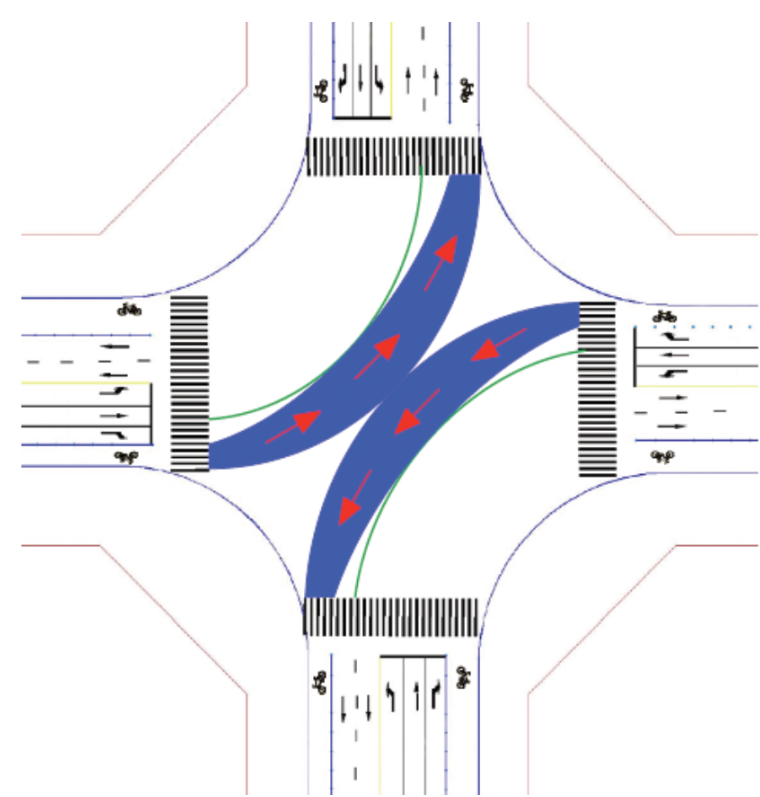

b)

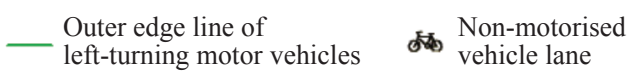

Figure 4 - Traffic space diagram of left-turning mopeds at signal-controlled intersections

entrances so that the analysis baseline of the ideal traffic space can be given, which is the midline of ideal traffic space of left-turning mopeds. In addition, three types of quantitative analysis indicators for the traffic characteristics of mopeds were proposed according to the different areas of the ideal traffic space.

\subsection{Determination of ideal traffic space of mopeds}

Figure 4 displays the ideal traffic space of left-turning mopeds (blue-filled area) and the driving directions of left-turning mopeds (red arrow lines) in different non-motorised lanes, and the outer edge liens of left-turning motor vehicles (green solid lines).

\subsection{Transverse distance referring to the midline of the ideal traffic space}

To quantify the scatter characteristics of mopeds in the process of passing intersections, the transverse distance was proposed which refers to the vertical distance between mopeds and the midline of left-turning traffic spaces. To capture the characteristics of the different stages of passing the intersection, three typical measuring sections were taken on the midline of each traffic space and defined as Sections I, II, III, respectively (Figure 5).

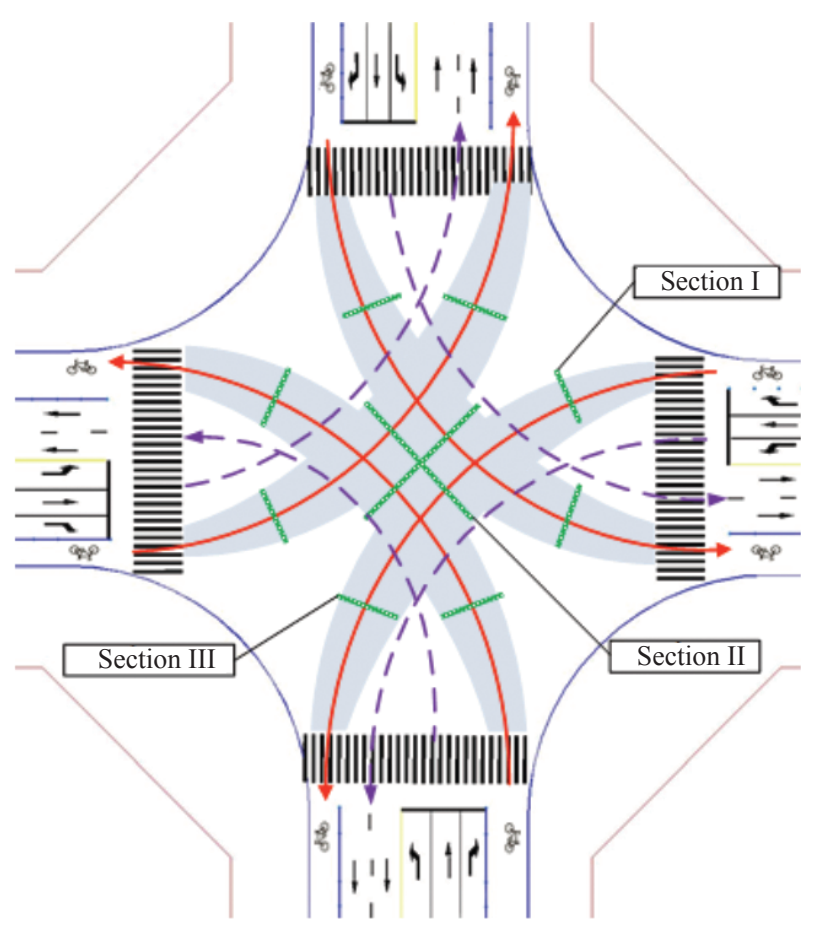

Ideal traffic space of left-turning mopeds

$\longrightarrow$ The midline of traffic space of left-turning mopeds

$\rightarrow$ Outer edge line of left-turning motor vehicles

Measuring section

Sob Non-motorised vehicle lane

Figure 5 - Schematic diagram of transverse distance calculation 


\subsection{The proportion of left-turning mopeds with crossing behaviour}

According to the recorded videos, the crossing behaviour signifying that left-turning mopeds crossed the outer edge of the left-turning motor vehicle was found. Figure 6 shows a trajectory of a moped with the crossing behaviour.

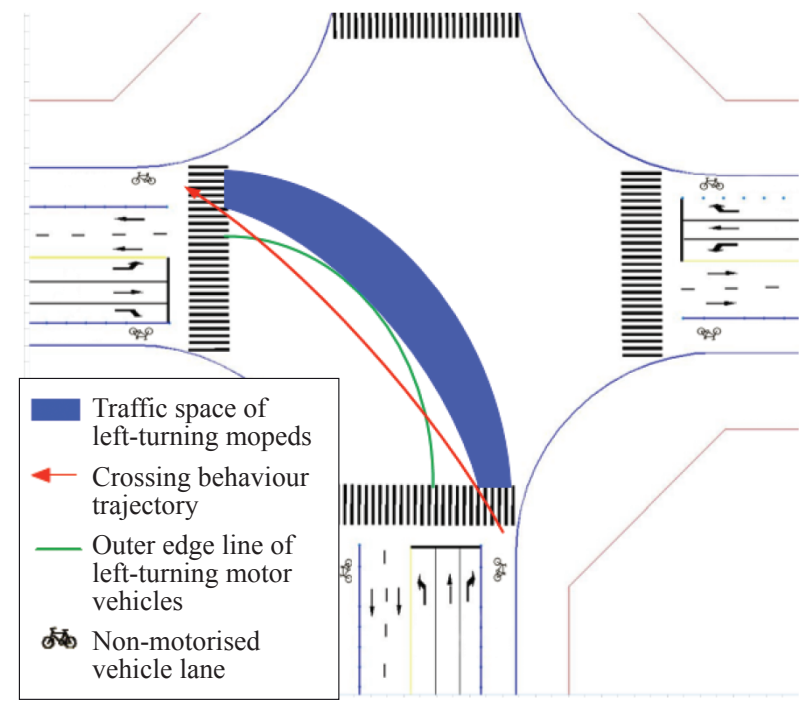

Figure 6-Schematic diagram of the trajectory of a moped with the crossing behaviour

Since the crossing behaviour of moped may be different under different left-turning motor vehicle flows, we analysed the crossing behaviour under different traffic operating conditions. The traffic conditions here can be characterised by the Volume-to-Capacity ratios (V/Cs), which are commonly used in traffic engineering, where V (unit: pcu per signal cycle, 'pcu' is the written abbreviation of 'passenger car unit') is the volume of left-turning vehicles, and $\mathrm{C}$ (unit: pcu per signal cycle) is the maximum actual traffic capacity of left-turning lanes at signal-controlled intersections. Here, the proportions of left-turning mopeds with crossing behaviour were defined to analyse the crossing behaviour, which refers to the number of mopeds with crossing behaviours that account for the total number of left-turning mopeds.

\subsection{Average number of avoidance behaviour of mopeds}

Avoidance behaviour of left-turning mopeds travelling in opposite directions refers to the behaviours used to prevent collisions and ensure driving safety when mopeds are turning left from opposite directions at the same time. Driving trajectories of mopeds travelling in opposite directions are presented in Figure 7. Here, the average number of avoidance behaviour during the left-turning phase is proposed under different flow rates of mopeds.

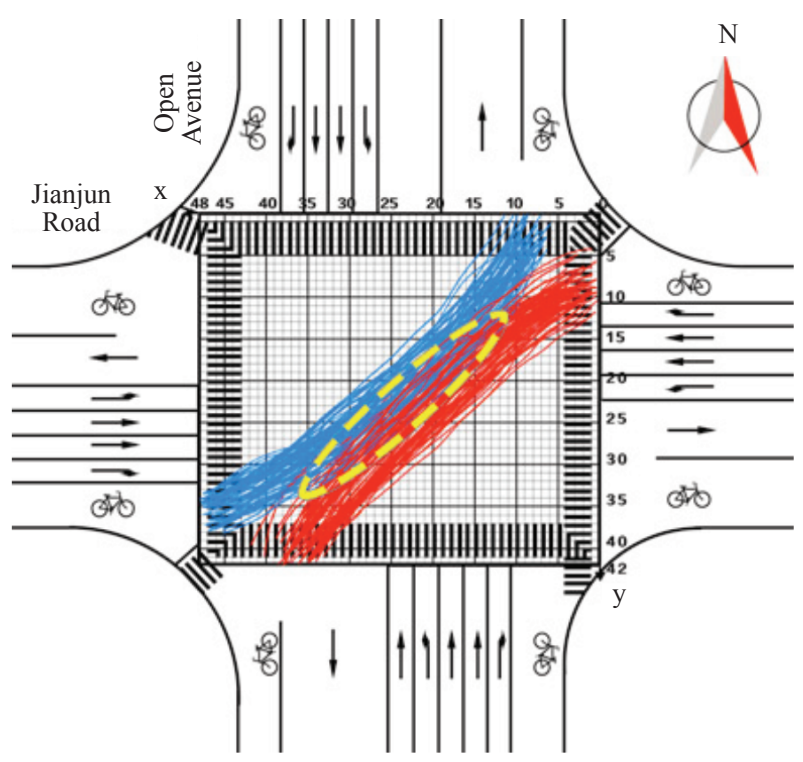

Figure 7 - Driving trajectories of mopeds travelling in opposite directions

\section{EMPIRICAL ANALYSIS}

\subsection{Qualitative analysis of riding characteristics of left-turning mopeds}

During red traffic lights, all mopeds gathered in front of the crosswalks and formed a queue. Each moped had a small lateral footprint. When traffic lights turned green, each moped started to accelerate, then advanced into the centre of intersections, and finally, they exited the intersections. There are three distinct features for mopeds through intersections: irregularity, clustering, and variability.

Irregularity. A left-turning moped is a non-selfbalancing system that sways from side to side while riding. Since a moped is in the same driving plane as motor vehicles at the intersection, it is easy for a moped to drive out of the non-segregated areas. However, the acceleration and braking of a moped are very different from those of a motor vehicle, which can cause moped riders to feel worried, and the moped may sway laterally, easily deviating from its original trajectory. Therefore, interference from surrounding mopeds and motor vehicles is observed. This phenomenon is manifested as irregularities in moped trajectories, as shown in Figure 8. 


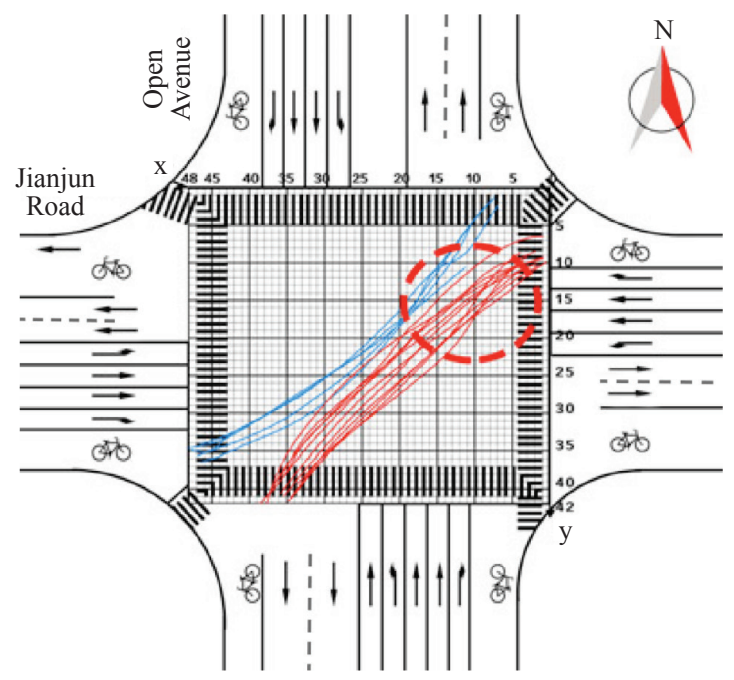

Figure 8 - The serpentine trajectories of left-turning mopeds

Clustering. After the traffic light turns green, the mopeds flock into the centre of an intersection. The transverse distance between the mopeds is small while riders wait during the red-light period. Therefore, as the vehicle starts to move, the running state of the vehicle will depend on the behaviour of other vehicles in the cluster. At intersections, many mopeds can amass in a short period, which can have an impact on the driving behaviour of motor vehicles (Figure 9).

Variability. Mopeds can easily turn, accelerate, and decelerate. Moreover, rider behaviour can vary greatly, and the speed and direction of an individual vehicle will often change suddenly. Therefore, riding positions of mopeds at intersections are relatively scattered, and riding behaviours are variable and difficult to control.

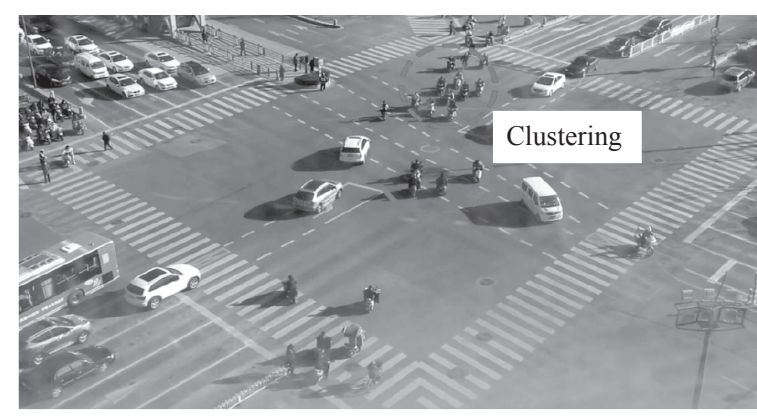

Figure 9-Clustering moped traffic

\subsection{Quantitative analysis of the characteristics of moped movement}

Next, three characteristics of mopeds are quantitatively analysed according to corresponding indicators based on the behaviour data extracted from the surveyed videos.
Asymmetrical characteristic behaviour

of mopeds on the midline of traffic space

Figure 10 demonstrates the relative frequency distribution of the transverse distance of mopeds at three selected sections. The following conclusions can be drawn: (1) On Section I, more than half of moped riders tend to ride in the left area of traffic space. The proportion of mopeds distributed in the left and right areas were $57 \%$ and $43 \%$, respectively. In addition, most of the transverse distance was distributed within 2.5 meters from the centreline, accounting for $84 \%$. This indicates that mopeds tend to ride in the middle of the traffic space when it starts to enter intersections (Figure 10a). (2) On Section II, some mopeds appeared to drive to the right area of traffic space, which may be caused by interference from motor vehicles or other mopeds on the left side. This phenomenon makes the ratio of mopeds on the left and right sides of the passage space the same. Besides, the proportion of mopeds concentrated on the midline of traffic space has also been reduced, only $71 \%$ of the mopeds within 2.5 meters from the centreline, $6 \%$ down from the previous period (Figure 10b). (3) On Section III, the proportion of mopeds on the right side was $4 \%$ higher than that of the left side, with the value of $52 \%$ and $48 \%$, respectively. $75 \%$ of the mopeds within 2.5 meters from the centreline, compared to the first stage and the second stage before dropped by $9 \%$ and $3 \%$, respectively. This implies that mopeds are relatively dispersed during the end phase of the left turn, indicating progressive diffusion characteristic along the left-turning direction (Figure 10c).

To sum up, it can be concluded that:

1) The moped riders deviated from the midline of ideal traffic space in the process of crossing these intersections;

2) The mopeds appeared to shift from the left area of the ideal traffic space to the right one in the process of crossing the intersection.

\section{Crossing behaviour of mopeds in the left-area of the traffic space}

Table 2 summarises the scenario parameters at surveyed intersections. Among them, the capacity and flow are for left-turning motor vehicles. In the context of three different $\mathrm{V} / \mathrm{Cs}$, the behaviour of mopeds crossing the outer edge line of the left-turning motor vehicles was analysed. 


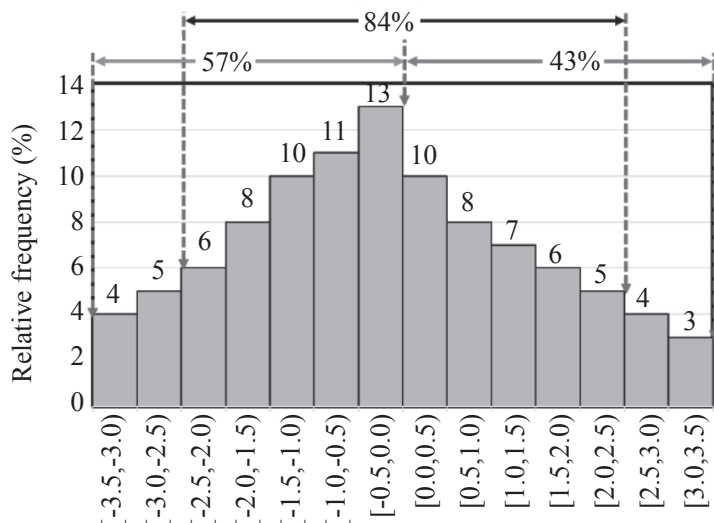

Transverse distance $[\mathrm{m}]$

a) Section $I$

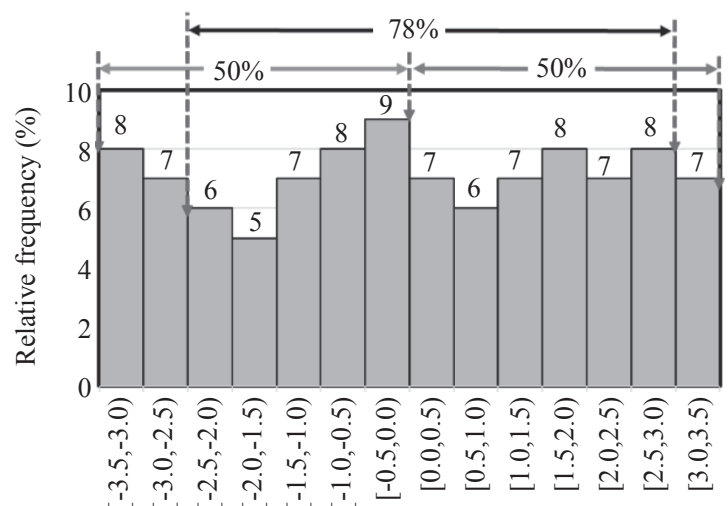

Transverse distance $[\mathrm{m}]$

a) Section II

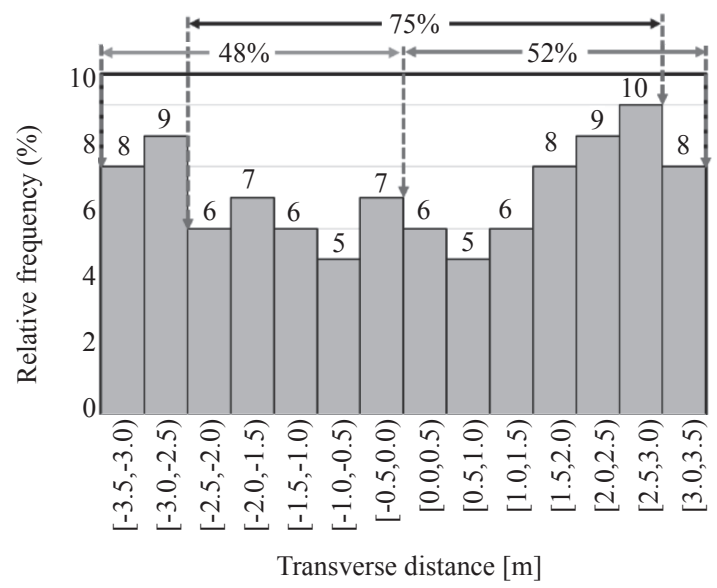

a) Section III

Figure 10 - Relative frequency distribution of transverse distance on different sections

Table 2 - Summary of scenario parameters at surveyed intersections

\begin{tabular}{|c|c|c|c|c|c|c|}
\hline \multirow[b]{2}{*}{ ID } & \multirow[b]{2}{*}{ Intersection name } & \multirow[b]{2}{*}{ Directions } & \multirow{2}{*}{$\begin{array}{c}\text { Actual traffic } \\
\text { capacity } \\
\text { (pcu/signal cycle) }\end{array}$} & \multicolumn{3}{|c|}{ Volume (pcu/signal cycle) } \\
\hline & & & & $\begin{array}{c}\mathrm{V} / \mathrm{C} \in \\
(0,0.3]\end{array}$ & $\begin{array}{c}\mathrm{V} / \mathrm{C} \in \\
(0.3,0.6]\end{array}$ & $\mathrm{V} / \mathrm{C}>0.6$ \\
\hline \multirow{2}{*}{1} & \multirow{2}{*}{ Kaifang Rd-Jianjun Rd } & East/West-bound & 22 & $(0,7]$ & {$[8,14]$} & $\geq 15$ \\
\hline & & North/South-bound & 18 & $(0,6]$ & {$[7,11]$} & $\geq 12$ \\
\hline \multirow{2}{*}{2} & \multirow{2}{*}{ Jianjun Rd-Wengang Rd } & East/West-bound & 20 & $(0,6]$ & {$[7,12]$} & $\geq 13$ \\
\hline & & North/South-bound & 20 & $(0,6]$ & {$[7,12]$} & $\geq 13$ \\
\hline \multirow{2}{*}{3} & \multirow{2}{*}{ Jianjun Rd-Renmin Rd } & East/West-bound & 22 & $(0,7]$ & {$[8,14]$} & $\geq 15$ \\
\hline & & North/South-bound & 20 & $(0,6]$ & {$[7,12]$} & $\geq 13$ \\
\hline \multirow{2}{*}{4} & \multirow{2}{*}{ Jianjun Rd-Jiefang Rd } & East/West-bound & 20 & $(0,6]$ & {$[7,12]$} & $\geq 13$ \\
\hline & & North/South-bound & 18 & $(0,6]$ & {$[7,11]$} & $\geq 12$ \\
\hline \multirow{2}{*}{5} & \multirow{2}{*}{ Daqing Rd-Wengang Rd } & East/West-bound & 22 & $(0,7]$ & {$[8,14]$} & $\geq 15$ \\
\hline & & North/South-bound & 18 & $(0,6]$ & {$[7,11]$} & $\geq 12$ \\
\hline
\end{tabular}


Figure 11 shows the relationship between the number of left-turning mopeds crossing the outer edge line of left-turning motor vehicles and the total number of left-turning mopeds under different $\mathrm{V} /$ Cs. The following results were obtained:

1) Under the same $\mathrm{V} / \mathrm{C}$, as the number of left-turning mopeds increased, the number of left-turning mopeds with crossing behaviour also increased linearly.

2) With the same number of left-turn mopeds, the higher the $\mathrm{V} / \mathrm{Cs}$, the smaller the number of mopeds with crossing behaviour. Also, as the number of left-turning mopeds increased, the difference in the number of mopeds with crossing behaviour under different $\mathrm{V} / \mathrm{C}$ was greater.

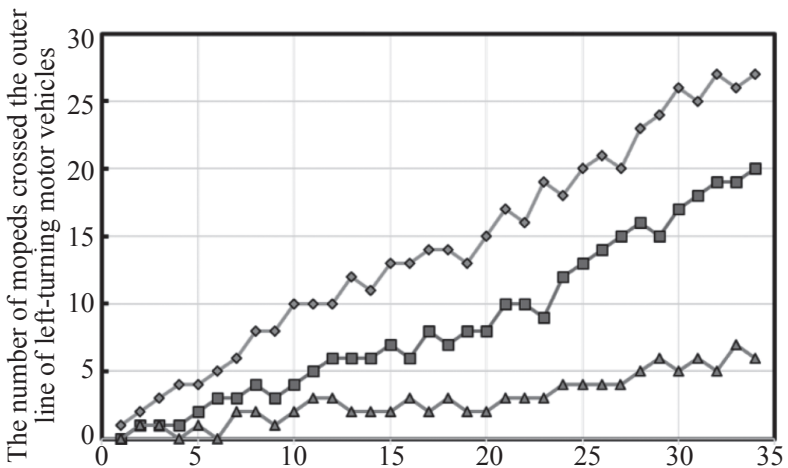

The number of mopeds (vehicles per signal cycle)

$\rightarrow \quad V / C \in(0,0.3]-\rightarrow V / C \in(0.3,0.6] \rightarrow V / C>0.6$

Figure 11 - The number of left-turning mopeds with the crossing behaviour under different $\mathrm{V} / \mathrm{Cs}$

Figure 12 presents the relationship between the proportion of left-turning mopeds with crossing behaviour and the number of mopeds under different $\mathrm{V} / \mathrm{Cs}$.

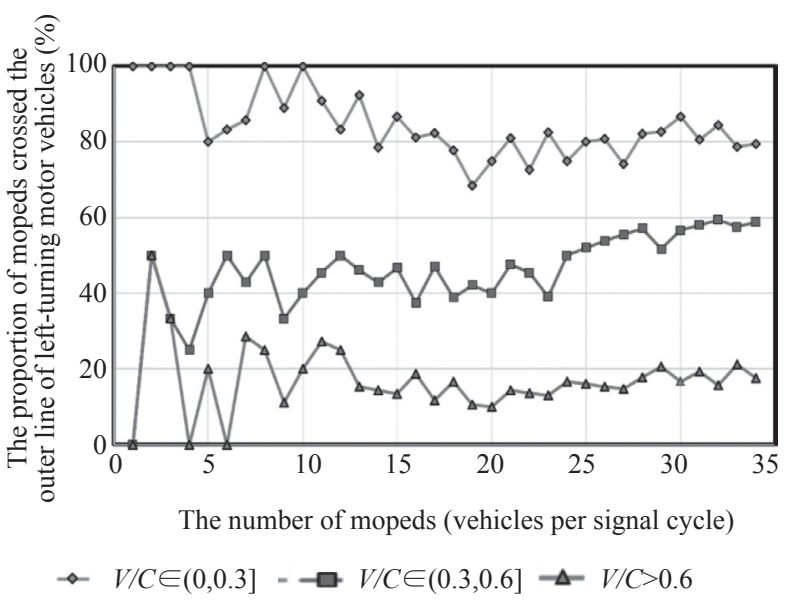

Figure 12 - Changes in the proportion of left-turning mopeds with crossing behaviour under different $V / C$
It can be found that: (1) generally, the higher the $\mathrm{V} / \mathrm{Cs}$, the lower the proportion of mopeds with crossing behaviour. This is because when the $\mathrm{V} /$ Cs were relatively high, the free space before and after motor vehicles that mopeds can pass through was small, which makes mopeds riders unwilling to take the risk to pass. (2) Under the same $\mathrm{V} / \mathrm{C}$, when the number of mopeds was less than 10 vehicles per signal cycle, the proportion of mopeds with crossing behaviour in the total left-turning mopeds changed relatively greatly. When the number of mopeds was greater than 10 vehicles per signal cycle, the proportion of mopeds with crossing behaviour in the total left-turning mopeds tended to be relatively stable, accounting for $80 \%, 60 \%$, and $20 \%$, respectively, of mopeds under three different V/Cs was greater.

\section{Analysis of avoidance behaviour of mopeds from the opposite directions}

Figure 13 describes the distribution of avoidance behaviours of mopeds from the opposite directions. It can be concluded that: (1) In general, avoidance behaviours were frequent for left-turning moped riders travelling in opposite directions, and the number of avoidance behaviours ranged from 0 to 6; (2) As the flow of mopeds increased over time, the number of avoidance behaviours of left-turning mopeds travelling in opposite directions increased. There is a linear relationship between the average number of avoidance behaviour and the flow rate of mopeds, and the regression coefficient was 0.9577. Based on this, it can be recommended that spatially separating left-turning mopeds into different entry

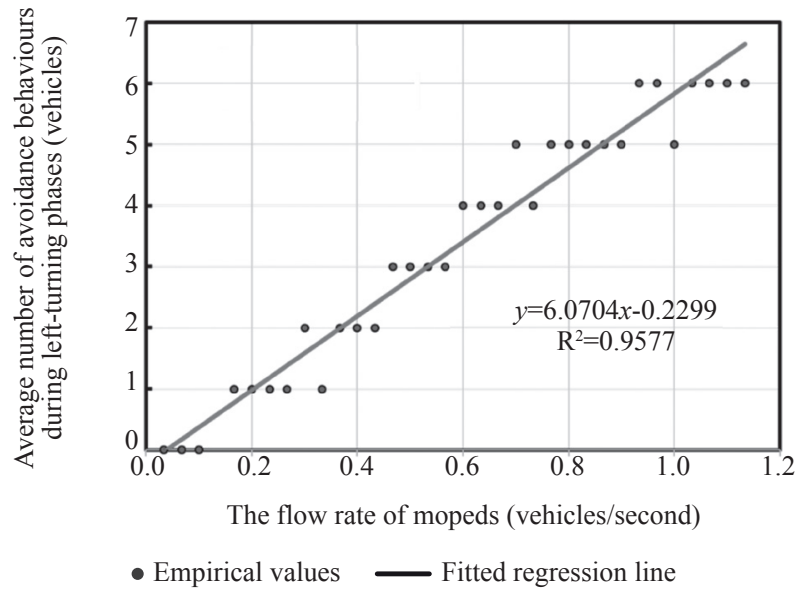

Figure 13 -Distribution of avoidance behaviours of mopeds from the opposite directions 
lanes can limit avoidance behaviours and effectively ensure the safety of mopeds passing through a signal-controlled intersection.

\section{CONCLUSIONS}

Understanding the behaviour of left-turning moped riders at signalised intersections is the basis for safe operation and management of intersections. To this end, we carried out a series of work from two aspects of acquiring the behaviour data of left-turning mopeds at signal-controlled intersections and analysing three behaviours of left-turning mopeds. The main results of this study can be summarised as follows:

1) A video conversion method of moped movement data acquisition was proposed and the effectiveness of the data acquisition method was also verified through a field experiment. The results showed that the errors of moped movement data obtained by video conversion method were within 0.1 meter, which satisfies the analysis of the moped riders' movement behaviour.

2) To analyse the characteristics of the left-turning mopeds at intersections, the ideal traffic space for left-turn mopeds from different entrances was defined. Based on this, three indicators, namely, transverse distance, the proportion of left-turning mopeds with crossing behaviour, and the average number of avoidance behaviour, were proposed and used to analyse the asymmetrical characteristics behaviour, crossing behaviour, and avoidance behaviour.

3) In terms of the asymmetrical characteristics behaviour, we found that the mopeds tended to shift from the left area of the ideal traffic space to the right one.

4) The higher the V/Cs of left-turning motor vehicles, the lower the proportion of mopeds with crossing behaviour.

5) There is a linear relationship between the average number of avoidance behaviour and the flow rate of mopeds.

Owing to limited time and resources, this paper has several limitations, which should be addressed in future research. We only considered the influence of moped traffic volumes and the traffic volumes of adjacent vehicles that crossed the lines of mopeds. At the same time, this paper did not analyse clusters of mopeds in different driving states that are related to signal lights.

\section{ACKNOWLEDGMENT}

This research was supported by the State Key Program of National Natural Science Foundation of China (Grant No.51338008).

韦凌翔1 Email: weilx@ycit.edu.cn 赵鹏飞2 Email: zhaopengfei@bucea.edu.cn 李宇轩3 Email: liyx_hello@emails.bjut.edu.cn 陈寅嘉1 Email: chenyinjia1413@163.com 廖明军 ${ }^{1}$ Email: mjliao@163.com 1 盐城工学院材料科学与工程学院, 江苏省盐城市建军路211号, 224051

2 北京建筑大学土木与交通工程学院, 北京市大兴区永源路15号, 102616

3 北京工业大学交通工程重点实验室, 北京市朝阳区平乐园100号，100124

信号交叉口左转电动车交通行为分析: 以中国 盐城为例

摘要

在中国骑行车 (电动自行车和轻型摩托车) 通 常用作个人交通工具, 但是在信号控制交叉口左转 骑行车的特性的研究相对缺乏, 因此本文对左转骑 行者的交通特性进行研究。首先提出了一种骑行车 交通数据采集的视频转换方法; 然后, 通过比较现 场实验和视频转换方法的结果, 对本方法进行了验 证; 其次, 定义了交叉口不同进口左转骑行车的理 想通行空间，以分析其交通特征；此外，提出了三 个指标 (横向距离、左转骑行车与左转机动车交叉 比例、对向左转骑行车避让行为的平均数量) 用于 分析非对称特征行为、交叉行为和回避行为; 最 后，基于从五个信号控制交叉口收集的视频数据分 析所提出方法的合理性。本文既提供了获取骑行车 位置数据的有效方法, 又为提高城市信号控制交叉 口左转骑行车驾驶安全性提供了可靠的理论依据。

\section{关键词}

交通工程; 骑行行为; 左转电动

车交通流；信号交叉口

\section{REFERENCES}

[1] Tal I, Ciubotaru B, Muntean GM. Vehicular-communications-based speed advisory system for electric bicycles. IEEE Transactions on Vehicular Technology. 2016;65(6): 4129-4143. DOI: 10.1109/TVT.2015.2442338

[2] Wei L, et al. Comparison study on travel characteristics between two kinds of electric bike. Procedia - Social and Behavioral Sciences. 2013;96: 1603-1610. DOI: 10.1016/j.sbspro.2013.08.182

[3] Shen JJ, Wang Q, Cao ZM. Correlation model between speed and density of electric bicycles at signalized intersections. Applied Mechanics \& Materials. 2015; 744-746: 1803-1807. DOI: 10.4028/www.scientific.net/ amm.744-746.1803

[4] Muetze A, Tan Y. Electric bicycles - A performance 
evaluation. Industry Applications Magazine IEEE. 2007;13(4): 12-21. DOI: 10.1109/mia.2007.4283505

[5] Yan X, et al. Electric bicycle cost calculation models and analysis based on the social perspective in China. Environmental Science \& Pollution Research. 2018;25(20): 20193-20205. DOI: 10.1007/s11356-018-2150-8

[6] Jones T, Harms L, Heinen E. Motives perceptions and experiences of electric bicycle owners and implications for health, wellbeing and mobility. Journal of Transport Geography. 2016;53: 41-49. DOI: 10.1016/j.jtrangeo.2016.04.006

[7] Tiefang $\mathrm{Z}$, et al. Injury source and correlation analysis of riders in car-electric bicycle accidents. Applied Bionics and Biomechanics. 2018;(2018): 1-15. DOI: 10.1155/2018/3674858

[8] Petzoldt $\mathrm{T}$, et al. Traffic conflicts and their contextual factors when riding conventional vs. electric bicycles. Transportation Research Part F: Traffic Psychology and Behaviour. 2017;46: 477-490. DOI: 10.1016/ j.trf.2016.06.010

[9] Feng Z, et al. Electric-bicycle-related injury: A rising traffic injury burden in China. Injury Prevention Journal of the International Society for Child \& Adolescent Injury Prevention. 2010;16(6): 417-419. DOI: 10.1136/ ip.2009.024646

[10] Chodur J, Ostrowski K, Tracz M. Variability of capacity and traffic performance at urban and rural signalised intersections. Transportation Research Procedia. 2016;15: 87-99. DOI: 10.1016/j.trpro.2016.06.008

[11] Castillo-Manzano JI, Castronuño M, Fageda X. Exploring the relationship between truck load capacity and traffic accidents in the European Union. Transportation Research Part E. 2016;88: 94-109. DOI: 10.1016/ j.tre.2016.02.003

[12] Zwahlen D, Jackowski C, Pfäffli M. Sleepiness, driving, and motorcycle accidents: A questionnaire-based survey. Journal of Forensic \& Legal Medicine. 2016;44: 183187. DOI: $10.1016 /$ j.jflm.2016.10.014

[13] Yang Q, et al. Analytical evaluation of the use of leftturn phasing for single left-turn lane only. Transportation Research Part B: Methodological. 2018;111: 266-303. DOI: $10.1016 /$ j.trb.2018.03.013

[14] Borrell B. The bicycle problem that nearly broke mathematics. Nature. 2016;535(7612): 338-341. DOI: $10.1038 / 535338 \mathrm{a}$

[15] Bai L, et al. Comparative analysis of risky behaviours of electric bicycles at signalized intersections. Journal of Crash Prevention \& Injury Control. 2015;16(4): 424428. DOI: $10.1080 / 15389588.2014 .952724$

[16] Rubin G, et al. Upper extremity open fractures in hospitalized road traffic accident patients: Adult versus pediatric cases. Journal of Orthopaedic Surgery \& Research. 2017;12(1): 1-5. DOI: 10.1186/s13018-017-0657-1

[17] Mellino S, et al. A life cycle assessment of lithium battery and hydrogen-FC powered electric bicycles: Searching for cleanersolutionstourbanmobility.InternationalJournalof Hydrogen Energy. 2017;42(3): 1830-1840. DOI: 10.1016/ j.ijhydene.2016.10.146

[18] Kerdsup B, Fuengwarodsakul NH. Performance and cost comparison of reluctance motors used for electric bicycles. Electrical Engineering. 2017;99(2): 475-486. DOI: 10.1007/s00202-016-0373-6

[19] Duan LL, Ye PP, Wang LH. Future challenges and solutions for safety in China: China CDC's exploration of injury prevention strategies. Global Health Journal. 2018;2(2): 14-23. DOI: 10.1016/s2414-6447(19)30135-6

[20] Gao W, et al. A study on cyclist head injuries based on an electric-bicycle to car accident reconstruction. Traffic Injury Prevention. 2020;21(8): 563-568. DOI: $10.1080 / 15389588.2020 .1821882$

[21] Leo C, et al. Analysis of Swedish and Dutch accident data on cyclist injuries in cyclist-car collisions. Traffic Injury Prevention. 2019;20(2): 1-3. DOI: 10.1080/15389588.2019.1679551

[22] Heylen D, et al. Ticks and tick-borne diseases in the city: Role of landscape connectivity and green space characteristics in a metropolitan area. The Science of the Total Environment. 2019;670(20): 941-949. DOI: 10.1016/ j.scitotenv.2019.03.235

[23] Juremalani J, Chauhan KA. Urbanization challenges in emerging economies. Energy and water infrastructure, transportation infrastructure, and planning and financing. ASCE India Conference, 12-14 December 2017, New Delhi, India. American Society of Civil Engineers; 2018. p. 688-696. Available from: https://searchworks.stanford. edu/view/13091641

[24] Wang Y, et al. Research on non-motorcycle traffic space optimization at signal control intersections. The $3^{\text {rd }}$ IEEE International Conference on Control Science and Systems Engineering (ICCSSE), 17-19 August 2017, Beijing, China. China Agricultural University; 2017. p. 766-769.

[25] Damsere-Derry J, Bawa S. Bicyclists' accident pattern in Northern Ghana. IATSS Research. 2017;42(3): 1-5. DOI: 10.1016/j.iatssr.2017.10.002

[26] Lee H, et al. A study on cyclist accident analysis on Korea roads with typology of iGLAD. Journal of Auto-vehicle Safety Association. 2018;10(1): 27-31.

[27] Otte D, Facius T. Accident typology comparisons between pedelecs and conventional bicycles. Journal of Transportation Safety \& Security. 2020;12(1): 116-135.

[28] Ou H, et al. Electric bicycle management and control at a signalized intersection. Physica A: Statistical Mechanics and its Applications. 2018;512: 1000-1008. DOI: 10.1016/j.physa.2018.06.116

[29] Liu M, Liu Y. Analyses and improvement options on road safety issues in Beijing. 2018 International Conference on Transportation \& Logistics, Information \& Communication, Smart City (TLICSC 2018), 30-31 October 2018, Chengdu City, China. Wuhan University of Technology; 2018. p. 382-386.

[30] Cherry C, Cervero R. Use characteristics and mode choice behaviour of electric bike users in China. Transport Policy. 2007;14(3): 247-257. DOI: 10.1016/j.tranpol.2007.02.005

[31] Fishman E, Cherry C. E-bikes in the Mainstream: Reviewing a Decade of Research. Transport Reviews. 2016;36(1): 72-91. DOI: 10.1080/01441647.2015.1069907

[32] Rose G. E-bikes and urban transportation: Emerging issues and unresolved questions. Transportation. 2011;39(1): 81-96. DOI: 10.1007/s11116-011-9328-y

[33] Wells P, Lin X. Spontaneous emergence versus technology management in sustainable mobility 
transitions: Electric bicycles in China. Transportation Research Part A. 2015;78: 371-383. DOI: 10.1016/ j.tra.2015.05.022

[34] Kuhnert PM, Do KA. Mcclure R. Combining non-parametric models with logistic regression: An application to motorcycle injury data. Computational Statistics \& Data Analysis. 2000;34(3): 371-386. DOI: 10.1016/S01679473(99)00099-7

[35] Yao L, Wu C. Traffic safety for electric bike riders in China: Attitudes, risk perception, and aberrant riding behaviours. Transportation Research Record: Journal of the Transportation Research Board. 2012;2314(1): 4956. DOI: $10.3141 / 2314-07$

[36] Dozza M, Fernandez A. Understanding bicycle dynamics and cyclist behaviour from naturalistic field data (November 2012). IEEE Transactions on Intelligent Transportation Systems. 2014;15(1): 376-384. DOI: 10.1109/ TITS.2013.2279687

[37] Jin S, et al. Estimating cycleway capacity and bicycle equivalent unit for electric bicycles. Transportation
Research Part A: Policy and Practice. 2015;77: 225-248. DOI: $10.1016 /$ j.tra.2015.04.013

[38] Wang XR, Han BR. Logistic regression analysis and nursing interventions for high-risk factors for pressure sores in patients in a surgical intensive care unit. Chinese Nursing Research. 2015;2(2-3): 51-54. DOI: 10.1016/j. cnre.2015.04.004

[39] Han P. Multiply robust estimation in regression analysis with missing data. Journal of the American Statistical Association. 2014;109(507): 1159-1173. DOI:10.1080/0 1621459.2014.880058

[40] Tang K, et al. Behavior of Riders of Electric Bicycles at Onset of Green and Yellow at Signalized Intersections in China. Transportation Research Record: Journal of the Transportation Research Board. 2012;2317(1): 85-96. DOI: $10.3141 / 2317-11$

[41] Popovich N, et al. Experiences of electric bicycle users in the Sacramento, California area. Travel Behaviour \& Society. 2014;1(2): 37-44. DOI: 10.1016/j.tbs.2013.10.006 